\title{
PHARMACIST INVOLVEMENT TO DECREASE DRUG-RELATED PROBLEMS AMONG GERIATRIC PATIENTS IN INDONESIAN PRIMARY HEALTH CENTERS
}

\author{
DESI SURYANI ${ }^{1}$, ANTON BAHTIAR ${ }^{2}$, RETNOSARI ANDRAJATI ${ }^{3 *}$ \\ ${ }^{1}$ Health Office in Karanganyar, Jawa Tengah, Indonesia. ${ }^{2}$ Department of Pharmacology and Toxicology, Faculty of Pharmacy, Universitas \\ Indonesia, Depok, Indonesia. ${ }^{3}$ Department of Clinical Pharmacy, Faculty of Pharmacy, Universitas Indonesia, Depok, Indonesia. \\ Email: andrajati@farmasi.ui.ac.id
}

Received: 21 April 2017, Revised and Accepted: 13 July 2017

\section{ABSTRACT}

Objective: The studies have demonstrated that older people often suffer from multiple diseases and are thus prescribed many different drugs. Therefore, drug-related problems (DRPs) are common in the elderly. The main objectives of this study were to reduce the number of DRPs in the elderly through pharmacist involvement and to analyze differences after pharmacist recommendations.

Methods: In a quasi-experimental study, 12 primary health centers were selected and randomly divided into two groups (six in each group). In the first group, the physicians received pharmacist recommendations verbally through discussions, and in the second group, the physicians received recommendations through letters. DRPs were analyzed from all older inpatients' medical records 1 month before and 1 month after the pharmacist recommendations. The main outcome being measured was the incidence of DRPs, classified into problems, and causes according to the Indonesian translated version of Pharmaceutical Care Network Europe, Version 6.2 (PCNE V 6.2). The problems were identified based on journal articles and other relevant literature.

Results: A total of 205 patients were analyzed before pharmacist intervention (Group 1: 121; Group 2: 84) and 202 patients after the intervention (Group 1: 108; Group 2: 94). The most common problem in these elderly patients was that they suffered from toxic effects. The most common cause was inappropriate drug selection. The number of DRPs and causes were decreased significantly through the discussions (Wilcoxon signed-rank test, problems $\mathrm{p}=0.027$, causes $\mathrm{p}=0.028$ ). DRPs were also significantly decreased through the recommendation letters (paired t-test, number of problems $\mathrm{p}=0.003$, and causes $\mathrm{p}=0.004)$. Discussion with physicians seemed more effective and decreased more problems ( $\mathrm{p}=0.001)$ and causes $(\mathrm{p}=0.002)$. Through discussions, the decrease in a number of problems was $20.83 \pm 8.931$, and the decrease in the number of causes was $25.33 \pm 11.431$ versus the recommendation letter, at $4.17 \pm 1.941$ and $5.17 \pm 2.483$, respectively.

Conclusion: Pharmacist involvement decreased DRPs among older inpatients. Discussing DRPs with the physicians treating the patients is more effective than giving recommendations in writing only. The PCNE V 6.2 DRP classification system is useful for documenting DRPs among the elderly as it can help pharmacists develop plans to reduce DRPs.

Keywords: Drug-related problem, Geriatric, Pharmaceutical Care Network Europe, Pharmacist, Primary Health Center, Indonesia.

(C) 2017 The Authors. Published by Innovare Academic Sciences Pvt Ltd. This is an open accessarticle under the CC BY license (http://creativecommons. org/licenses/by/4. 0/) DOI: http://dx.doi.org/10.22159/ajpcr.2017.v10s5.23109

\section{INTRODUCTION}

A drug-related problem (DRP) is an event or circumstance involving drug therapy that actually or potentially interferes with the desired health outcome [1]. Drug therapy can effectively improve quality of life and treat, prevent, or alleviate the symptoms of a disease, but undesirable reactions and DRPs are common in geriatrics [2]. This is likely due to the fact that geriatrics often have multiple comorbidities and are therefore prescribed multiple medications [3]. However, age-related physiological changes in geriatrics may alter the pharmacokinetic and pharmacodynamic properties of drugs [3], and all pharmacokinetic steps may be affected in the elderly. Most of the organ systems in the elderly are more susceptible; hence, the adverse effect of drugs may be magnified. As a result, these pharmacological changes in the elderly leave them more vulnerable to DRPs [4].

The studies conducted by Bero (1991), Roughead (1998), and Cooper (1999) showed that $15-22 \%$ of hospitalized elderly patients were admitted because of DRPs [3]. A study by Blix et al. showed that about $81 \%$ of patients admitted to the hospital experienced DRP s, with an average of 2.1 clinically relevant DRPs per patient [5]. A study of 100 elderly patients who were hospitalized in the Dr. Sardjito Hospital at Yogyakarta, Indonesia, showed that DRPs occurred in $79.2 \%$ of patients, with at least one DRP per patient (maximum five DRPs), and a total of 121 DRPs were identified [6]. Yet, Beijer and de Blaey (2002) reported that the majority of adverse drug reactions in the elderly can be prevented [3]

The previous studies have shown that pharmacist involvement is important for helping improve prescribing physicians' ability to identify, prevent, and resolve DRPs [5,6]. Pharmacist involvement in this study was performed by providing information to the prescribing physicians [1]. Information was provided to one group of physicians verbally through discussions between the pharmacist and the physician, and in the other group, the pharmacist gave only a written recommendation to the physician about geriatric DRPs that were identified.

The DRP identification tool used in this study was the most recent DRP classifications from the Pharmaceutical Care Network Europe, Version 6.2 (PCNE V 6.2). A pertinent difference with this version versus previous versions of PCNE and other classification systems is that this version separates the problem (that affects or is going to affect the outcome) from its cause [1]. 
Karanganyar is a district in the Central Java Province where the population aged 60 years and above reached $12.35 \%$ by June 2011 . As a result, a well-planned elderly health program has been promoted there since 2013. The health efforts in the program include preventive, curative, and rehabilitative areas, recognizing that pharmaceutical care plays an important role in optimizing health outcomes for geriatric patients. Pharmaceutical care is defined as a direct, responsible provision of medication-related care for the purpose of achieving definite outcomes that improve a patient's quality of life [7]. Pharmaceutical care involves not only medication therapy (the actual provision of medications) but also decisions about medication use for individual patients; the decision when to not use a medication; judgement of medication selection, dosages, routes, and methods of administration; medication therapy monitoring; and the provision of medication-related information and counseling to individual patients [7]. Pharmaceutical care involves having the cooperation of the dispensing pharmacist with both patients and other healthcare professionals in designing, implementing, and monitoring drug therapy for patients [8]. Three major functions of pharmaceutical care are to identify DRPs, resolution of DRPs, and prevention of potential DRPs $[7,8]$. The main objectives of this study were to reduce the number of DRPs in the elderly through pharmacist involvement and to analyze any differences in outcomes due to pharmacist recommendations. The specific objectives of this study were to obtain descriptions about geriatric patient DRPs before and after pharmacist recommendations; to analyze the relationship between the variables of age, number of medications, and treatment duration with the number of problems and causes before and after pharmacist recommendations; to evaluate the effectiveness of recommendations made through either verbal discussion or written recommendation; and to evaluate changes in DRPs with the different modes of recommendation.

\section{METHODS}

Legal approval from the body of the National Well-Being, Politics, and Public Protection was obtained, and all parties included in this research were asked for their consent, including primary health center chiefs and their medical teams. A quasi-experimental study $[9,10]$ was designed. 12 primary health centers were randomly divided into two groups (six in each group). In the first group, the physicians received pharmacist recommendations verbally through discussions, and in the second group, the physicians received recommendations through letters. All geriatric inpatients in government primary health centers who met the inclusion criteria were included as the subjects. The inclusion criteria for geriatric patients were those aged $\geq 60$ years who received drug treatment and were hospitalized in the primary health center for a predetermined period. The exclusion criterion was incomplete medical records (missing sex, age, diagnosis, medications used, or patient progress during hospitalization). The DRPs were obtained through analyzing the geriatric inpatients' medical records both 1 month before and 1 month after the pharmacist recommendations were made. Normally, distributed data were analyzed parametrically, whereas abnormally distributed data were analyzed non-parametrically. A paired t-test and Wilcoxon signed-rank test were performed to compare before to after pharmacist involvement (pre-test and posttest). An independent t-test was performed to obtain the difference between the discussion and the recommendation letter groups.

\section{RESULTS}

A total of 407 geriatric inpatients from 12 primary health centers were included in this research. It consisted of 205 patients before the intervention (Group 1: 121, Group 2: 84) and 202 patients after the intervention (Group 1: 108, Group 2: 94). The translated version (Indonesian language) of the PCNE V 6.2 DRP classification system (the sections entitled "the problems" and "the causes") [1] that had been face validated by 12 clinical pharmacists from the Master's Degree Program in Pharmaceutical Science, Faculty of Pharmacy, University of Indonesia, was used as a tool to classify DRPs. DRPs, in this article, were provided in the English only for easier understanding.
The problems and their causes

The types and number of problems and causes in this study can be seen in Figs. 1 and 2. Each problem is typically caused by one or more factors. Not every cause can lead to an actual problem, but they are important predictors that a problem could occur.

\section{Inappropriate drug (including contraindicated): C 1.1}

Inappropriate drugs (including contraindicated drugs), C 1.1, referred to the use of potentially inappropriate drugs for geriatrics, such as diazepam, metoclopramide, non-steroidal anti-inflammatory drugs (NSAIDs), and loperamide. In most of the cases, in this study, diazepam had been prescribed as a sleep aid and/or muscle relaxant. It had frequently been continued for several days, and in some cases, it was prescribed at patient's discharge for a longer time. Diazepam is considered to be an inappropriate drug in geriatric care because it has a long half-life of around 20-50 hrs, which may increase in older adults up to approximately $90 \mathrm{hrs}$, and is contraindicated in those with hepatic disorders [11]. Desmethyldiazepam, a metabolite of diazepam, has a half-life of 50-100 hrs, which can be prolonged in older adults. Hence, diazepam accumulation is extensive [11]. Benzodiazepines can be used in seizure disorders, rapid eye movement sleep disorders, benzodiazepine and ethanol withdrawal, severe generalized anxiety disorder, periprocedural anesthesia, and end-of-life care, but it is also associated with an increased risk of cognitive impairment, delirium, and falls in geriatric patients [12]. Benzodiazepines (all types) are not recommended for the treatment of insomnia, agitation, or delirium [12]. If benzodiazepines were indicated, the pharmacist recommendation was to switch to one of the benzodiazepines that have a shorter duration of action. Alprazolam is considered to be the benzodiazepine of choice in the elderly due to its shorter duration of action [11]

In this study, metoclopramide injections were prescribed to treat and prevent vomiting. Metoclopramide has a potential central nervous system (CNS) adverse drug reactions such as extrapyramidal effects, including tardive dyskinesia, which has a higher risk of occurring in geriatrics [11,12]. Pharmacist recommendation was to stop metoclopramide injections if the patients were able to take oral medications, or metoclopramide could be replaced with drugs having fewer adverse effects, such as domperidone syrup $3 \times 10 \mathrm{mg} 1 / 2 \mathrm{hr}$ before mealtime. Research on metoclopramide and domperidone for diabetic gastroparesis showed that the two drugs have similar efficacy, but domperidone has fewer side effects of somnolence, akathisia, asthenia, anxiety, depression, and problems with mental acuity [13].

NSAIDs were prescribed as the initial and ongoing treatment for pain in this study. Although proton-pump inhibitors can be given to prevent or reduce NSAID-associated ulcers [14], NSAID use in geriatrics can increase the risk of acute renal failure by 58\%, and NSAID users have a three-fold greater risk of acute renal failure than non-NSAIDs users [15]. Research has also shown that aspirin can trigger asthma. Patients who are sensitive to aspirin are usually also sensitive to other NSAIDs, but also having sensitivity to acetaminophen [16] is rare. Pharmacist recommendations to physicians were to avoid the use of NSAIDs whenever possible if the patient presented with nausea and vomiting, if the patient was suspected of experiencing gastritis/ulcers in the gastrointestinal tract or of renal failure, or if the patient had a history of asthma. Drugs with less prostaglandin activity, such as acetaminophen, may be used as an alternative [15] at doses of 325-650 mg every 4-6 hrs [11]. Unlike acetylsalicylic acid and other NSAIDs, paracetamol has little anti-inflammatory activity, which limits its usefulness for long-term treatment of pain associated with inflammation. However, it is useful in the management of osteoarthritis, a condition with only a small inflammatory component [17].

Diphenhydramine was primarily prescribed as a sleep aid in this study, and it was often prescribed for several days. Diphenhydramine's elimination half-life in adult patients is $2-10 \mathrm{hrs}$, which is increased to $13.5 \mathrm{hrs}$ in geriatrics. Due to its sedative and anticholinergic properties, diphenhydramine should not be considered as a long-term therapy 
in geriatrics. Diphenhydramine as a geriatric sleep aid was also not recommended because of its anticholinergic properties [11]

Loperamide was prescribed by physicians for diarrhea that was presumed to be caused by bacterial infection. Most patients want

Table 1: Type and number of problems identified

\begin{tabular}{lll}
\hline Types of problems & \multicolumn{2}{c}{ Number of problems } \\
\cline { 2 - 3 } & $\begin{array}{l}\text { Before pharmacist After pharmacist } \\
\text { recommendations }\end{array}$ & recommendations \\
\hline $\begin{array}{l}\text { P 1.1: No effect of drug } \\
\text { treatment/therapy failure }\end{array}$ & 7 & 0 \\
P 1.2: Effect of drug & 32 & 2 \\
treatment not optimal & & \\
$\begin{array}{l}\text { P 1.4: Untreated indication } \\
\text { P 2.1: Adverse drug }\end{array}$ & 9 & 23 \\
event (non-allergic) & 23 & 18 \\
P 2.3: Toxic adverse drug & 132 & 37 \\
event & & 0 \\
P 3.1: Drug treatment more & 4 & 0 \\
$\begin{array}{l}\text { costly than necessary } \\
\text { P 3.2: Unnecessary drug } \\
\text { treatment }\end{array}$ & 2 & \\
\hline
\end{tabular}

Table 2: Type and number of causes identified

\begin{tabular}{lll}
\hline Types of causes & \multicolumn{2}{c}{ Number of causes } \\
\cline { 2 - 3 } & $\begin{array}{l}\text { Before pharmacist } \\
\text { recommendations }\end{array}$ & $\begin{array}{l}\text { recommendations } \\
\text { remarmacist }\end{array}$ \\
\hline $\begin{array}{l}\text { C 1.1: Inappropriate } \\
\text { drug (incl. contraindicated) }\end{array}$ & 150 & 52 \\
$\begin{array}{l}\text { C 1.2: No indication for } \\
\text { drug }\end{array}$ & 6 & 0 \\
$\begin{array}{l}\text { C 1.3: Inappropriate } \\
\text { combination of drugs, or } \\
\text { drugs and food }\end{array}$ & 69 & 11 \\
$\begin{array}{l}\text { C 1.6: Too many drugs } \\
\text { prescribed for indication }\end{array}$ & 2 & \\
$\begin{array}{l}\text { C 3.3: Dosage regimen not } \\
\text { frequent enough }\end{array}$ & 14 & 0 \\
$\begin{array}{l}\text { C 5.4: Drug not taken/ } \\
\text { administered at all }\end{array}$ & 9 & 1 \\
\hline
\end{tabular}

their diarrhea to be stopped immediately when they arrive at a primary health center. Of the cases identified in this study, one patient manifested abdominal pain that led to the physician stopping the drug. Loperamide's mechanism of action is inhibition of peristalsis and prolonging of intestinal transit time [11]. The antidiarrheal properties of loperamide are associated with inhibition of smooth muscle motors, thus delaying the passage of fluid through the intestine and increasing the capacitance. Loperamide is used for chronic diarrhea associated with inflammatory bowel disease, acute nonspecific diarrhea, and increased debit volume of ileostomy. Loperamide is contraindicated in acute dysentery, bacterial enterocolitis, and pseudomembranous enterocolitis [11]. Peristaltic inhibition is associated with significant sequelae such as the ileus, megacolon, and toxic megacolon. Peristaltic inhibition facilitates the contact of organisms such as Entamoeba histolytica to the mucosal wall, which causes damage to the mucosa, necrosis of the intestinal wall, and dilatation [18]. Pharmacist recommendation was to avoid loperamide use in infectious gastroenteritis, in patients with symptoms of rectal bleeding, and when the patients had a fever [18].

\section{No indication for the drug: C 1.2}

No indication for the drug (C 1.2) was related to the use of antibiotics (e.g., chloramphenicol, ciprofloxacin, and amoxicillin) in patients where no signs of infection had been recognized (e.g., temperature was within normal range, normal respiratory rate, normal leukocyte values, and no examination or laboratory results that showed an infected state). The use of simvastatin without a blood cholesterol level test and no history of hypertension or other cardiovascular disease were also included in this classification.

Inappropriate combinations of drugs, or drugs and food: C 1.3 Some interactions were found, such as furosemide and digoxin, combinations of two or more NSAIDs, NSAIDs and captopril, NSAIDs and furosemide, antacids and a ferrous compound, ciprofloxacin and antacids, ciprofloxacin and aminophylline, and cotrimoxazole and captopril.

Digoxin toxicity may increase if given with furosemide. It has been predicted that glycoside works by inhibiting the $\mathrm{Na}+\mathrm{K}+-$ ATPase pump [19]. Potassium is an intracellular cation essential for cardiac muscle contraction and transmission of nerve impulses in the heart. Loss of potassium due to diuretics may exacerbate the loss of potassium in heart muscle cells, resulting in an increase in the activity and toxicity of digitalis. Diuretics also contribute to magnesium loss [19].

Table 3: Correlation of age, number of medications, and length of stay with the number of geriatric DRP problems and causes in Karanganyar's primary health centers

\begin{tabular}{|c|c|c|c|c|}
\hline \multirow[t]{3}{*}{ Variables } & \multicolumn{2}{|l|}{ Number of problems } & \multicolumn{2}{|l|}{ Number of causes } \\
\hline & \multicolumn{2}{|l|}{$\mathbf{r}_{s}(\mathbf{p})$} & \multicolumn{2}{|l|}{$\mathbf{r}_{s}(\mathbf{p})$} \\
\hline & $\begin{array}{l}\text { Before pharmacist } \\
\text { involvement }\end{array}$ & $\begin{array}{l}\text { After pharmacist } \\
\text { involvement }\end{array}$ & $\begin{array}{l}\text { Before pharmacist } \\
\text { involvement }\end{array}$ & $\begin{array}{l}\text { After pharmacist } \\
\text { involvement }\end{array}$ \\
\hline Age & $0.065(0.357)$ & $-0.062(0.337)$ & $0.106(0.132)$ & $-0.051(0.475)$ \\
\hline Number of medication & $0.314 *(0.000)$ & $-0.024(0.734)$ & $0.319 *(0.000)$ & $-0.031(0.659)$ \\
\hline Length of stay & $0.236 *(0.001)$ & $0.061(0.386)$ & $0.208^{*}(0.003)$ & $0.074(0.297)$ \\
\hline
\end{tabular}

$\mathrm{r}_{\mathrm{s}}=$ Spearman's correlation coefficient. ${ }^{*}$ Correlated, significant at $\mathrm{p}<0.05$. DRP: Drug-related problems

Table 4: Difference of geriatric patient DRPs before and after pharmacist involvement in Karanganyar's primary health centers

\begin{tabular}{|c|c|c|c|c|c|c|}
\hline & Discussion & letter & Discussion & $\begin{array}{l}\text { cdramemdatidution } \\
\text { letter }\end{array}$ & Discussion & $\begin{array}{l}\text { Recommendation } \\
\text { letter }\end{array}$ \\
\hline Mea & $24.67 \pm 6.683$ & $10.17 \pm 5.115$ & $3.83 \pm 3.656$ & $6.00 \pm 6.512$ & $0.027^{*}$ & $0.003^{*}$ \\
\hline Mean number of causes $\pm S D$ & $29.83 \pm 8.819$ & $11.83 \pm 6.401$ & $4.50 \pm 3.987$ & $6.67 \pm 7.312$ & $0.028^{*}$ & $0.004^{*}$ \\
\hline
\end{tabular}

*The difference was statistically significant at $\mathrm{p}<0.05$ based on Wilcoxon signed-rank test. ${ }^{\#}$ The difference was statistically significant at $\mathrm{p}<0.05$ based on paired $\mathrm{t}$-test. SD: Standard deviation, DRP: Drug-related problems 
Table 5: A comparison of DRP decrease with different modes of pharmacist recommendations

\begin{tabular}{lll}
\hline Variable & Pharmacist recommendation & \multicolumn{1}{c}{$\mathbf{p}$} \\
\cline { 2 - 3 } & Discussion & Recommendation letter \\
\hline Decrease in the number of problems \pm SD & $20.83 \pm 8.931$ & $4.17 \pm 1.941$ \\
Decrease in the number of causes \pm SD & $25.33 \pm 11.431$ & $5.17 \pm 2.483$ \\
\hline
\end{tabular}

*The difference was statistically significant at $\mathrm{p}<0.05$ based on independent $\mathrm{t}$-test. SD: Standard deviation, DRP: Drug-related problems

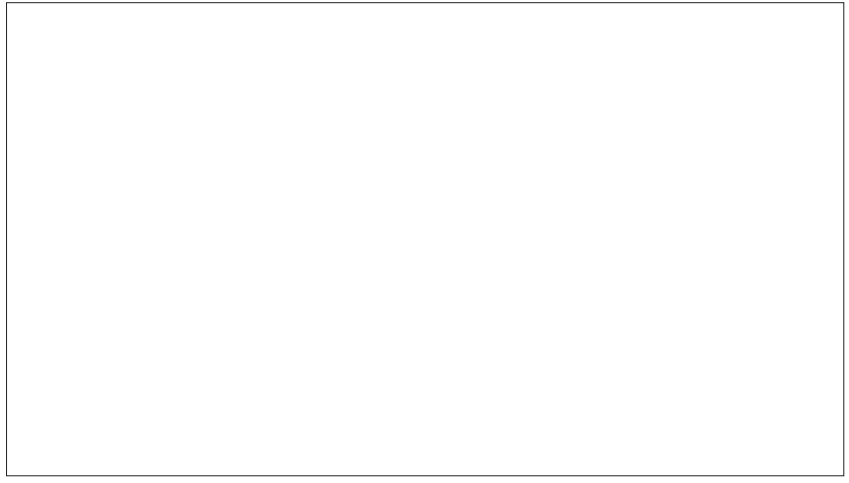

Fig. 1:

Magnesium is also an important cation, and life-threatening conditions such as paralysis and cardiac arrhythmias can occur because of hypomagnesemia, making the proper recognition and treatment of these problems of paramount importance [15]. Pharmacist recommendations included the need for monitoring digoxin and electrolyte levels in the blood, especially potassium and magnesium levels, and to correct levels if patients experienced hypokalemia or hypomagnesemia. Unfortunately, no laboratory facilities performing electrolyte tests or therapeutic drug monitoring were available at the primary health centers.

Combinations of two or more NSAIDs may increase the risk of stomach bleeding [19], the combination of diuretics with NSAIDs increases the risk of nephrotoxicity due to volume depletion, and NSAIDs combined with angiotensin-converting enzyme (ACE) inhibitors can cause or increase the risk of acute renal failure and hyperkalemia, especially in geriatrics and dehydrated patients [11,20,21]. ACE inhibitors decrease synthesis of angiotensin II, causing dilation of the efferent arteriole (blood vessels that exit from the glomerulus), thereby reducing the glomerular capillary hydrostatic pressure necessary to reduce glomerular ultrafiltration. Renal prostaglandin inhibition by NSAIDs also causes water retention that could affect antihypertensive therapy and increase blood pressure [19].

Ciprofloxacin, in this study, was given with antacids or within a $1 / 2 \mathrm{hr}$ after antacids. Serum antibacterial levels can drop below the minimum inhibitory concentration or become subtherapy. The suspected underlying mechanism is the chelate formation between functional groups (3-carboxyl and 4-oxo) of aluminum and magnesium ions in the gastrointestinal tract. Pharmacist recommendation was to separate the route of administration or to give ciprofloxacin at least $2 \mathrm{hrs}$ before and not $<4-6$ hrs after the administration of antacids [19].

Ciprofloxacin interaction with theophylline may increase serum levels of theophylline, thereby increasing the toxicity of theophylline. Ciprofloxacin is an inhibitor of the CYP $1 \mathrm{~A} 2$ enzyme, whereas theophylline is a CYP $1 \mathrm{~A} 2$ substrate [16]. CYP inhibitors competitively and reversibly bind the active site on the enzyme, thus preventing the substrate from binding the same site and preventing the substrate from being metabolized [11]. Aminophylline was prescribed to treat asthmatic patients in this study. Theophylline, when dosed alone in the elderly, should be started at a $25 \%$ reduction of the normal adult dose and should not exceed a dose of $400 \mathrm{mg} /$ day in

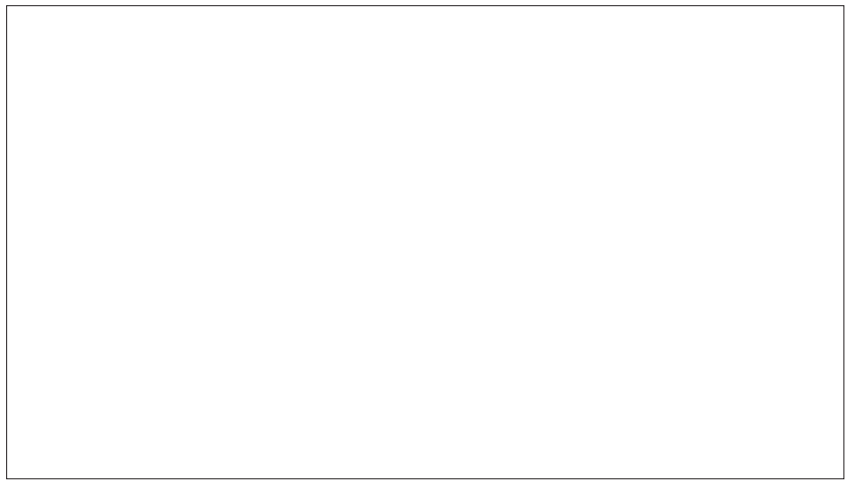

Fig. 2:

population groups with cardiac decompensation, cor pulmonale, and/or liver dysfunction [11]. Due to wide interpatient variability for half-lives of methylxanthines [11], pharmacist recommendation was theophylline serum level monitoring to optimize therapy and prevent serious toxicity. Unfortunately, serum levels of theophylline could not be accessed, which made testing the effects of the therapy difficult. Therefore, pharmacist recommendation was amended to substitution of aminophylline with salbutamol because no serum level measurement would be needed.

Some patients in this study received a protussive in combination with an antitussive, a combination that is considered irrational (though still controversial) [22]. Pharmacist recommendation for these cases was selection of only one of the drugs for different kinds of coughs and only if it was really necessary for the patients. No mucolytic agents are consistently effective at relieving coughs in patients with bronchitis, although they may be somewhat useful. Protussive agents are effective for increasing spending coughing, but the efficacy of long-term use has not been established. Antitussive agents may be beneficial for patients with chronic bronchitis but have very little efficacy in patients with upper respiratory tract infections [23].

Hyperkalemia has been reported to occur with use of cotrimoxazole alone. This effect is associated with the trimethoprim component, which has potassium-sparing properties in the distal renal tubule [19]. ACE inhibitors can decrease aldosterone synthesis, thereby reducing the loss of potassium from the kidneys. Thus, the interaction between cotrimoxazole and ACE inhibitors is probably due to the additive nature of both mechanisms coupled with decreased or impaired renal function [19].

\section{Too many drugs prescribed for indication: C 1.6}

Too many drugs prescribed for indication (C 1.6) were associated with the use of $2 \times 8 \mathrm{mg}$ intravenous (IV) ondansetron plus $2 \times 20 \mathrm{mg}$ famotidine tablets plus $2 \times 50 \mathrm{mg}$ IV ranitidine for dyspepsia. Pharmacist recommendation to physicians was to stop ondansetron and ranitidine injections because the patient was able to take oral medication.

Dosage regimen not frequent enough: $C 3.3$

Dosage regimen not frequent enough (C 3.3) was associated with ranitidine injections for gastritis and peptic ulcer at doses of 
$1-2 \times 50 \mathrm{mg}$ IV in patients who could not receive oral medication. The recommendations given were to increase ranitidine injection administration frequency to $50 \mathrm{mg}$ every 6-8 hrs [11]. A dosage adjustment was needed if the patient had impaired renal function [11]. Since ranitidine is a drug that is known to have CNS adverse effects [11], an acute confused state or delirium may occur in the elderly, so patients should be monitored for adverse effects. Pharmacist recommendations included using proton-pump inhibitors as a safer choice when the patient had been able to take oral medications.

\section{Drug not taken/administered at all: C 5.4}

Drug not taken/administered at all (C 5.4) in this study was associated with some cases of vomiting, constipation, and anemia. Vomiting in geriatrics leads to a worse quality of life because they cannot take oral medications, eat, or drink. Anemia in patients with hemoglobin (Hb) $<6$ g\% almost always requires a blood transfusion [24], and such patients were referred to a hospital. In patients with stable $\mathrm{Hb}$ of 6-10 $\mathrm{g} \%$, the decision for transfusion was based on an evaluation of clinical status. Patients with $\mathrm{Hb}$ above $10 \mathrm{~g} \%$ rarely require transfusion [24]. Cases of anemia in the elderly patients in this study were usually not urgent and were caused by the lack of nutrients needed for hematopoiesis. The preferred strategy, based on the cause, was the administration of nutrients such as Fe, Vitamin B12, folic acid, or recombinant erythropoietin [24].

\section{Correlation of age, number of medications, and length of stay with the number of geriatric DRP problems and causes}

The number of medications and length of stay in primary health centers were factors that correlated with the number of DRP problems and causes before pharmacist recommendations were given and none of these three factors correlated to the number of DRP problems and causes after pharmacist recommendations were given.

\section{Difference in geriatric patient DRPs before and after pharmacist recommendations}

Pharmacist involvement decreased DRPs among geriatric inpatients in all 12 primary health centers. The number of problems and causes were decreased significantly through the verbal discussions (Wilcoxon signed-rank test, problems $p=0.027$, causes $p=0.028$ ) and through written recommendation letters (paired t-test, number of problems $p=0.003$ and causes $p=0.004)$. The most common problems before and after pharmacist involvement were P 2.3 (patients suffering from toxic effects), with 132 problems (63.2\%) and 37 problems (62.7\%) in Group 1 and Group 2, respectively. Following pharmacist involvement, the most common causes were C 1.1 (inappropriate drug selection, including contraindications), with 150 causes $(60.0 \%)$ before, and 52 causes $(76.1 \%)$ afterward.

Differences in DRPs with different modes of pharmacist recommendations

Discussion with physicians seemed more effective and decreased more problems $(\mathrm{p}=0.001)$ and causes $(\mathrm{p}=0.002)$. Through discussions, the decrease in a number of problems was $20.83 \pm 8.931$, and the decrease in the number of causes was $25.33 \pm 11.431$ versus the recommendation letter, at $4.17 \pm 1.941$ and $5.17 \pm 2.483$, respectively.

\section{DISCUSSION}

Three factors were tested for their correlation to the number of problems and causes: Patient age, number of medications, and length of stay. Number of medications and length of stay in primary health centers were factors correlated to the number of the problems and causes before pharmacist recommendations. None of these three factors correlated to the number of the problems and causes after pharmacist recommendations, probably due to the recommendations reducing the impact of those factors. In this study, each geriatric patient was receiving around seven kinds of drugs. The elderly frequently experiences multiple illnesses and thus consumes numerous medications $[25,26]$. Looking at this data, the pharmaceutical care principles should be applied and prioritized for geriatric patients in primary health centers to achieve a reduction in DRPs.

The types of DRPs identified in this study differed from the previous research conducted by Chan et al. [3] where the most common problems were drugs not taken (35\%) but were in accordance with Hanlon et al. [2], where adverse drug reactions were common in geriatric patients. Types of DRPs in this study are difficult to compare with the previous studies using the PCNE V 6.2 classification system because of variations in the research setting and the health-care process experienced by patients. These results were consistent with research conducted by Viktil et al. [24] showing that an increasing number of drugs correlated with an increasing occurrence of DRPs. The duration of treatment was positively correlated with undesirable drug reactions [24]. The patient's age before and after the recommendations were not correlated and had no effect on the occurrence of DRPs, almost in line with the research conducted by Koh et al. [27], which proposed that age does not significantly affect DRPs but the number of the drugs was an important predictor. Increasing age in geriatric patients in this study probably caused physicians to give extra attention to prescribed medication.

None of the three factors was correlated with the number of DRP causes and problems after recommendations were given. The recommendations were effective in overcoming DRPs caused by these factors. A Wilcoxon signed-rank test and paired t-test were performed to compare DRPs before and after recommendations, as the data had a dependency. Patients in the same primary health center were treated by the same physician or medical team. Comparisons of decreasing number in DRPs to the previous studies are difficult because of variations in demographic and clinical conditions experienced by patients. Independent t-tests were used in this study to test the differences between the discussion and recommendation letter groups since data being compared did not have a dependency. The result was consistent with research conducted by Abraham and Devi [28] in that the recommendation made by pharmacists in discussions of DRPs with prescribers proved to reduce the incidence of DRPs. The results were also consistent with the study conducted by Rahayu et al. [29], which showed that a notification letter given to prescribers could reduce DRPs.

Both modes of recommendation given to the prescribers can cause a decrease in DRPs, but discussion was a better solution for decreasing DRPs. These results were consistent with Arnold and Straus [30] who asserted that learning with interactive meetings is more effective than didactic learning. In that study, the use of written learning material caused only a slight or no change in prescribing associated with excessive use of antibiotics for viral infections, appropriate antibiotic selection, and duration of antibiotic use. In contrast to written materials that may not have been read by the prescriber, discussion directly resolved any unclear information between prescribers and the pharmacist. Limitations in the study include the following: (1) identification was based on patient medication records, with limited supporting data; (2) diagnostic tests and laboratory results were obtained from simple equipment that was less sophisticated than in a reference hospital; and (3) interventions were given only to the prescribers and not directly to the patients. Product availability did not arise as a factor that influenced the results or implementation of the recommendations. Despite the limitations, this study's geriatric inpatients all fulfilled the criteria for inclusion, and the study had the participation of all primary health centers in one district. Thus, it can be expected that pharmacist involvement will decrease the number of patients hospitalized in reference hospital due to DRPs. Suggestions for the next study include assessing the necessity of giving the interventions directly to patients. In addition, many factors that are predicted to influence results need to be controlled.

\section{CONCLUSION}

The most common geriatric patient problem in Karanganyar's primary health-care sites was the potential of suffering toxic effects, and the most common cause was inappropriate drug selection. Pharmacist 
involvement decreased geriatric inpatient DRPs, and discussion of potential DRPs with the physicians treating the patients proved more effective than giving recommendations in writing only. Further, the PCNE V 6.2 DRP classification system proved useful in documenting DRPs among the elderly, as it can help pharmacists to develop plans to reduce DRPs. This research also reinforced the role of pharmacists in implementing pharmaceutical care principles to identify, prevent, and resolve DRPs in Indonesian primary health centers.

\section{REFERENCES}

1. Pharmaceutical Care Network Europe. Classification for Drug-Related Problems Help (Revised 14-01-2010vm) V6.2. PCNE

Classification. \: Pharmaceutical Care Network Europe; 2010. p. 1-9.

2. Hanlon JT, Lindblad CI, Hajjar ER, McCarthy TC. Update on drug-related problems in the elderly. Am J Geriatr Pharmacother 2003;1(1):38-43

3. Chan DC, Chen JH, Kuo HK, We CJ, Lu IS, Chiu LS, et al. Drugrelated problems (DRPs) identified from geriatric medication safety review clinics. Arch Gerontol Geriatr 2012:54(1):168-74

4. Mangoni AA, Jackson SH. Age-related changes in pharmacokinetics and pharmacodynamics: Basic principles and practical applications. Br J Clin Pharmacol 2004;57(1):6-14.

5. Blix HS, Viktil KK, Reikvam A, Moger TA, Hjemaas BJ, Pretsch P, et al. The majority of hospitalised patients have drug related problems; result from prospective study in general hospital. Eur J Clin Pharmacol 2004;60(9):651-8.

6. Rahmawati F, Sulaiman SA, Pramantara ID, Rochmah W. Involvement of Ward Pharmacist During Theurapeutic Process in Hospitalised Geriatric Patients in Dr. Sardjito Hospital Yogyakarta Indonesia; 2012. p. 1-11. Available from: http://www.mfk.farmasi.ugm.ac.id/files/news/ Full_paper_ACCP_Hongkong_Fita.pdf.

7. van Mil JW, Fernandez-Llimos F. What is "pharmaceutical care" in 2013? Pharm Pract (Granada) 2013;11(1):1-2.

8. Sreelalitha N, Vigneshwaran E, Narayana G, Reddy P, Reddy R. Review of phaemaceutical care services provided by the pharmacists. Int Res J Pharm 2012;3(4):76-9.

9. Levy Y, Ellis TJ. A guide for novice researchers on experimental and quasi-experimental studies in information systems research. Interdiscip J Inf Knowl Manage 2011;6:151-61.

10. Harris AD, McGregor JC, Perencevich EN, Furuno JP, Zhu J, Peterson DE, et al. The use and interpretation of quasi-experimental studies in medical informatics. J Am Med Inform Assoc 2006;13(1):16-23.

11. Shah RR. Drug development and use in the elderly: Search for the right dose and dosing regimen (Parts I and II). Br J Clin Pharmacol 2004;58(5):452-69.

12. American Geriatric Society 2012 Beers Criteria Update Expert Panel. American Geriatrics Society updated beers criteria for potentially inappropriate medication use in older adults. J Am Geriatr Soc 2012;60(4):616-31.
13. Sugumar A, Singh A, Pasricha PJ. A systematic review of the efficacy of domperidone for the treatment of diabetic gastroparesis. Clin Gastroenterol Hepatol 2008;6(7):726-33.

14. Huerta C, Castellsague J, Varas-Lorenzo C, García Rodríguez LA. Nonsteroidal anti-inflammatory drugs and risk of ARF in the general population. Am J Kidney Dis 2005;45(3):531-9.

15. Somberg JM. Pharmacotherapy: A pathophysiologic approach. Am J Ther 2007;14(4):418

16. Jenkins C, Costello J, Hodge L. Systematic review of prevalence of aspirin induced asthma and its implications for clinical practice. BMJ 2004;328(7447):434

17. Mehta DK, Ryan RS, Hogerzeil HV. WHO Model Formulary. London: Royal Pharmaceutical Society of Great Britain; 2004.

18. McGregor A, Brown M, Thway K, Wright SG. Fulminant amoebic colitis following loperamide use. J Travel Med 2007:14(1):61-2.

19. Honore PH. Drug interactions. Eur J Hosp Pharm 2014;21(2):73.

20. Fournier JP, Sommet A, Bourrel R, Oustric S, Pathak A, Lapeyre-Mestre $\mathrm{M}$, et al. Non-steroidal anti-inflammatory drugs (NSAIDs) and hypertension treatment intensification: A populationbased cohort study. Eur J Clin Pharmacol 2012;68(11):1533-40.

21. Rogulj D, Hauptfeld M, Iskra MS, Zorko VK, Strasek M. Extreme hyperkalaemia caused by concomitant use of a NSAID and an ace inhibitor in an elderly patient. Arh Hig Rada Toksikol 2010;61(2):241-5

22. McConnell KJ, Newlon C, Dickerhofe J. A model for continuing pharmacy education. Am J Pharm Educ 2009;73(5):87.

23. Bolser DC. Cough suppressant and pharmacologic protussive therapy: ACCP evidence-based clinical practice guidelines. Chest 2006;129 1 Suppl:238S-49.

24. Liumbruno G, Bennardello F, Lattanzio A, Piccoli P, Rossetti G. Recommendations for the transfusion of red blood cells. Blood Transfus 2009;7(1):49-64

25. Linjakumpu T, Hartikainen S, Klaukka T, Veijola J, Kivelä SL, Isoaho R. Use of medications and polypharmacy are increasing among the elderly. J Clin Epidemiol 2002;55(8):809-17.

26. Viktil KK, Blix HS, Moger TA, Reikvam A. Polypharmacy as commonly defined is an indicator of limited value in the assessment of drug-related problems. Br J Clin Pharmacol 2007;63(2):187-95.

27. Koh Y, Kutty FB, Li SC. Drug-related problems in hospitalized patients on polypharmacy: The influence of age and gender. Ther Clin Risk Manag 2005;1(1):39-48

28. Abraham RR, Devi AS. Drug related problems and reactive pharmacist interventions for patients receiving cardiovascular drugs. Am J PharmTech Res 2012;2(3):42-8.

29. Rahayu R, Andrajati R, Supardi S. Effect of drug information on doctors on decreased incidence of Drug Related Problems (PTO) on prescription of heart and blood vessel disease in Apotek X Jakarta. Bul Penelit Kesehatan 2010;38(3):147-59.

30. Arnold SR, Straus SE. Interventions to improve antibiotic prescribing practices in ambulatory care. Cochrane Database Syst Rev 2005;4:CD003539. 